\title{
Ursolic Acid Reduces Mycobacterium tuberculosis- Induced Nitric Oxide Release in Human Alveolar A549 cells
}

\author{
Tamanna Zerin', Minjung Lee ${ }^{1}$, Woong Sik Jang ${ }^{2}$, Kung-Woo Nam ${ }^{3}$, and Ho-yeon Song ${ }^{1, *}$
}

\begin{abstract}
Alveolar epithelial cells have been functionally implicated in Mycobacterium tuberculosis infection. This study investigated the role of ursolic acid (UA) - a triterpenoid carboxylic acid with potent antioxidant, anti-tumor, anti-inflammatory, and anti-tuberculosis properties in mycobacterial infection of alveolar epithelial A549 cells. We observed that M. tuberculosis successfully entered A549 cells. Cytotoxicity was mediated by nitric oxide (NO). A549 toxicity peaked along with NO generation $72 \mathrm{~h}$ after infection. The NO generated by mycobacterial infection in A549 cells was insufficient to kill mycobacteria, as made evident by the mycobacteria growth indicator tube time to detect (MGIT TTD) and viable cell count assays. Treatment of mycobacteria-infected cells with UA reduced the expression of inducible nitric oxide synthase, NO generation, and eventually improved cell viability. Moreover, UA was found to quench the translocation of the transcription factor, nuclear factor kappa B (NF-kB), from the cytosol to the nucleus in mycobacteria-infected cells. This study is the first to demonstrate the cytotoxic role of NO in the eradication of mycobacteria and the role of UA in reducing this cytotoxicity in A549 cells.
\end{abstract}

\section{INTRODUCTION}

Mycobacterium tuberculosis is the etiological agent of tuberculosis (TB). Inhalation of $M$. tuberculosis into the lungs leads to infection (Smith et al., 1966). The host response first involves cells of the innate immune system. Among these cells, macrophages are vital in host defense. However, alveolar epithelial cells are also infected by mycobacteria (Bermudez and Young,

\footnotetext{
${ }^{1}$ Department of Microbiology, School of Medicine, Soonchunhyang University, Cheonan 330-090, Korea, ${ }^{2}$ Regional Innovation Center, Soonchunhyang University, Asan 336-745, Korea, ${ }^{3}$ Department of Life Science and Biotechnology, College of Natural Science, Soonchunhyang University, Asan 336-745, Korea

${ }^{*}$ Correspondence: songmic@sch.ac.kr
}

Received 26 November, 2014; revised 10 May, 2015; accepted 14 May 2015; published online 18 June, 2015

Keywords: anti-tuberculosis, inducible nitric oxide synthase (iNOS), Mycobacterium tuberculosis, nuclear factor kappa B (NF-kB), ursolic acid
1994; Mapother and Sanger, 1984; Shepard, 1955). It is possible that both alveolar epithelial cells and mycobacteria play important roles in the microenvironment in the quelling and establishment of TB infection, respectively.

Little is known about the role of alveolar epithelial cells in the pathogenesis of TB. One of the likely mediators of antimycobacterial activity is nitric oxide (NO), which is produced by oxidation of L-arginine by the enzyme nitric oxide synthase (NOS) (Stuer et al., 1989). In macrophages, NO, with other toxic superoxide radicals within acidic phagosomes, is vital in limiting mycobacteria (Chan et al., 1992). However, excessive generation of NO may lead to cytotoxic effects and DNA damage, which may lead to cell death through activation of p53 and poly (ADP-ribose) polymerase (Eizirik et al., 1996; Ignarro, 2000). The role of NO in alveolar epithelial cells during mycobacteria infection is not well elucidated.

Ursolic acid (UA; 3-beta-3-hydroxy-urs-12-ene-28-oic-acid) is a pentacyclic triterpenoid carboxylic acid with several biological and pharmacological effects, including anti-inflammatory, antioxidant, anti-proliferative, anti-cancer, anti-mutagenic, antiatherosclerotic, anti-hypertensive, anti-leukemic, and antiviral activities in a number of experimental systems (Ikeda et al., 2008; Tsai and Yin, 2008). Additionally, recent studies demonstrated the anti-TB effects of UA through immunomodulation and activation of intracellular mycobactericidal activity (Jiménez-Arellanes et al., 2013; Podder et al., 2015). UA is found in a number of foods, including apples, basil, bilberries, cranberries, elder flower, peppermint, rosemary, lavender, oregano, thyme, hawthorn, and prunes (Liu, 1995). Natural compounds enriched in terpenoids have a strong potential to act as inhibitors of the activation of the immune-regulatory transcription factor, nuclear factor-kappa B (NF-kB) (De las Heras et al., 2003).

The present study involved alveolar epithelial A549 cells. This cell line has been used to study various intracellular pathogens such as Mycoplasma pneumonia and Chlamydia pneumonia (Yang et al., 2002; 2003). Infection of A549 cells by $M$. tuberculosis upregulates inducible nitric oxide synthase (iNOS) and increases NO levels (Roy et al., 2004). However, the excessive generation of $\mathrm{NO}$ can be cytotoxic for the neighboring cells (Eizirik et al., 1996; Ignarro, 2000), and administration of certain compounds may be required to improve cell viability. Since macrophages and epithelial cells in the lung may respond differently to mycobacterial infection and/or UA treatment, the present study explored the effect of UA on mycobacteriainfected lung epithelial cells. However, the role of infection 
and/or UA treatment in the context of cell survival and NO generation in $M$. tuberculosis-infected epithelial cells was explored.

\section{MATERIALS AND METHODS}

\section{Alveolar epithelial cells, chemicals, and treatment} conditions

Type II human alveolar A549 cells were purchased from American Type Culture Collection (USA). Cells were maintained in Dulbecco's Modified Eagle's Medium (DMEM) supplemented with $10 \%(\mathrm{v} / \mathrm{v})$ heat-inactivated fetal bovine serum (FBS) and $1 \%(\mathrm{v} / \mathrm{v})$ antibiotic/antimycotic cocktail $\left(100^{\circ} \mathrm{U} / \mathrm{ml}\right.$ penicillin, 100 $\mu \mathrm{g} / \mathrm{ml}$ streptomycin, and $0.25 \mu \mathrm{g} / \mathrm{ml}$ amphotericin B; Invitrogen, USA) in a humidified atmosphere of $5 \% \mathrm{CO}_{2}$ at $37^{\circ} \mathrm{C}$. Cells were seeded $\left(5 \times 10^{5} \mathrm{cells} / \mathrm{ml}\right)$ in six-well tissue culture plates overnight until they reached a confluence of $75-85 \%$. Immediately before infection or treatment, cells were replaced with serum-free DMEM media. UA and the competitive nitric oxide synthase inhibitor, $N^{G}$-monomethyl-L-arginine (L-NMMA), were obtained from Sigma-Aldrich (USA). Throughout the study, cells were treated with $10 \mu \mathrm{g} / \mathrm{ml}$ UA and $5 \mathrm{mM} \mathrm{L-NMMA}$ for $6 \mathrm{~h}$ following establishment of $M$. tuberculosis infection and then incubated for the desired times.

\section{Mycobacteria}

M. tuberculosis H37Rv was purchased from ATCC and cultured in Middlebrook $7 \mathrm{H} 11$ agar for 22 days. Isolated colonies were inoculated in Middlebrook $7 \mathrm{H} 9$ broth in a shaking incubator for 15 days. Because of the tendency of mycobacteria to form clumps, the suspension was vortexed vigorously and passed through an 8- $\mu \mathrm{m}$ filter to form a single-cell suspension. The suspension was allowed to stand for $3 \mathrm{~min}$, the upper twothird was removed, and the cell concentration was measured at $600 \mathrm{~nm}$ using McFarland standards. In addition, $10 \mu \mathrm{l}$ bacterial suspension was inoculated in Middlebrook $7 \mathrm{H} 11$ agar to establish the exact number of bacteria in the inoculum. The measured bacterial suspension was dispensed in aliquots and kept as a single lot at $-20^{\circ} \mathrm{C}$. Infection of $\mathrm{A} 549$ cells was carried out using this lot at an infecting ratio of cells to bacteria of $1: 10$.

Infection of A549 cells by M. tuberculosis H37Rv and resazurin assay

A549 cells $\left(1 \times 10^{5}\right.$ cells $\left./ \mathrm{ml}\right)$ were grown in a six-well tissue culture plate overnight. The culture medium was removed and replenished by warm DMEM without FBS. Cells were infected with $M$. tuberculosis H37Rv (multiplicity of infection 10) for the desired time at $37^{\circ} \mathrm{C}$ in a $5 \% \mathrm{CO}_{2}$ atmosphere. Following incubation, cells were washed three times with warm phosphatebuffered saline (PBS) to remove extracellular bacteria. The final extracellular wash medium was collected and $100 \mu \mathrm{l}$ was inoculated in $4.9 \mathrm{ml}$ of Middlebrook $7 \mathrm{H} 9$ broth followed by growth in a shaking incubator for 15 days. The intracellular bacteria were released by incubation of cells with $1 \mathrm{ml} 0.1 \%$ Triton $\mathrm{X}-100$ in sterile water for $10 \mathrm{~min}$. Samples were harvested and vigorously vortexed. One hundred microliters was inoculated in $4.9 \mathrm{ml}$ of Middlebrook $7 \mathrm{H} 9$ broth and incubated for 15 days as before described. Following incubation, a resazurin assay was performed. In brief, $200 \mu \mathrm{l}$ of culture grown in $7 \mathrm{H} 9$ medium was added to a 96-well tissue culture plate with uninoculated medium as the negative control for mycobacterial growth. Then, $30 \mu \mathrm{l}$ of $0.02 \%$ resazurin was added and incubated for $24 \mathrm{~h}$. The representative picture was taken, and fluorescence intensity was measured in a Victor ${ }^{\mathrm{T} M} \mathrm{X} 3$ Multilabel reader (Perkin Elmer, USA) at excitation and emission wavelengths of
530 and $590 \mathrm{~nm}$, respectively. Both the final wash medium and suspension following cell lysis were also plated on $7 \mathrm{H} 11$ agar to confirm the absence of extracellular mycobacteria (data not shown).

\section{Cell viability assay}

The cell viability assay is based on the conversion of 3-(4,5dimethylthiazol-2-yl)-2,5-diphenyltetrazolium bromide (MTT) to formazan crystal by mitochondrial dehydrogenase enzyme. A549 cells were grown in a 96-well tissue culture plate overnight to a confluence of about $80 \%$. The cells were infected and/or treated as required. Following incubation, $20 \mu \mathrm{l}$ of 5 $\mathrm{mg} / \mathrm{ml} \mathrm{MTT}$ were added to $200 \mu \mathrm{l}$ of cell suspension and incubated at $37^{\circ} \mathrm{C}$ for $4 \mathrm{~h}$. The medium was aspirated and the purple formazan crystal was dissolved by adding $100 \mu$ of dimethyl sulfoxide. After $30 \mathrm{~min}$ of incubation at $37^{\circ} \mathrm{C}$ in the dark, the absorbance was measured at $570 \mathrm{~nm}$ using a Victor $^{\mathrm{TM}} \mathrm{X} 3$ Multilabel reader (Perkin Elmer, USA).

\section{NO release assay}

The concentration of nitrite produced as a means to measure NO was measured using Griess reagent system (Promega, USA). In brief, supernatants of infected and/or treated cells for specified time points were collected and centrifuged at $400 \times g$ for $8 \mathrm{~min}$ to remove cells. In the meantime, nitrite standards were prepared by diluting $100 \mu \mathrm{M}$ nitrite solution up to $1.56 \mu \mathrm{M}$ by two-fold dilution. Cell-free $50 \mu \mathrm{l}$ supernatants and nitrite standards were added in 96-well tissue culture plates in triplicate. Subsequently, $50 \mu \mathrm{M}$ sulfanilamide solution was added to each well and incubated at room temperature for 5-10 min followed by addition of $50 \mu \mathrm{M} \mathrm{N}$-1-napthylethylenediamine dihydrochloride. After 5-10 min, the absorbance was measured at $540 \mathrm{~nm}$ in the aforementioned Multilabel reader.

\section{MGIT 960 system and viability counts}

A549 cells were seeded, infected with $M$. tuberculosis H37Rv for $2 \mathrm{~h}$, and incubated for $0-72 \mathrm{~h}$. At each time point, cells were disrupted by $0.1 \%$ Triton X-100 and harvested. Two hundred microliters of cell lysate was inoculated in a BACTEC MGIT 960 tube (Becton Dickinson, USA) following supplementation with $800 \mu \mathrm{l}$ growth supplement (Becton Dickinson). BACTEC MGIT 960 tubes were incubated at $37^{\circ} \mathrm{C}$ in the BACTEC MGIT 960 instrument, in which they were automatically monitored each hour for fluorescence development for 42 days or until a positive signal developed by time to detection (TTD). The same inoculum was used to inoculate Middlebrook $7 \mathrm{H} 11$ agar, which was incubated at $37^{\circ} \mathrm{C}$ for 3 weeks. These cultures were inspected weekly or until mycobacterial colonies were seen. The colonies were counted. Colony forming units (CFUs) were calculated taking the dilutions in consideration.

\section{Cytosolic and nuclear protein extraction}

Cytosolic and nuclear proteins were extracted according to the company protocol (BioVision, USA). Briefly, cells were harvested by centrifugation after the desired infection and/or treatment for desired time points. Cytosol extraction buffer A (CEB-A) was added $(200 \mu \mathrm{l})$ to the cell pellet, vortexed vigorously, and incubated on ice for $10 \mathrm{~min}$. Cytosol extraction buffer B (CEB-B) was added $(11 \mu \mathrm{l})$, vortexed vigorously, centrifuged at $16,000 \times$ $g$ for $5 \mathrm{~min}$, and the supernatant containing cytoplasmic extract was collected. The pellet was re-suspended in $20 \mu$ of nuclear extraction buffer (NEB), repeatedly vortexed, and kept on ice for $10 \mathrm{~min}$. Finally, it was centrifuged at $16,000 \times \mathrm{g}$ for $10 \mathrm{~min}$, and the supernatant containing the nuclear extract was collected. 
A

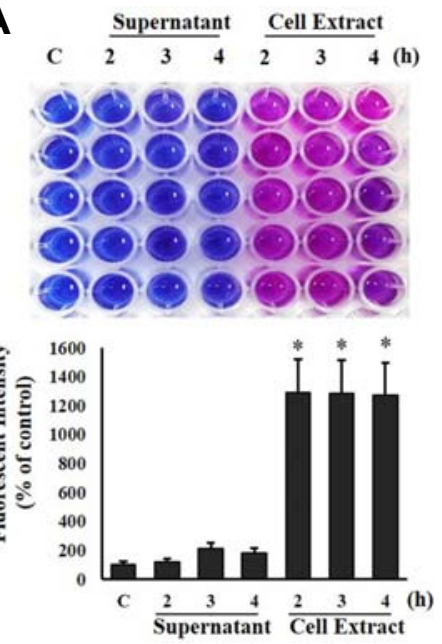

B

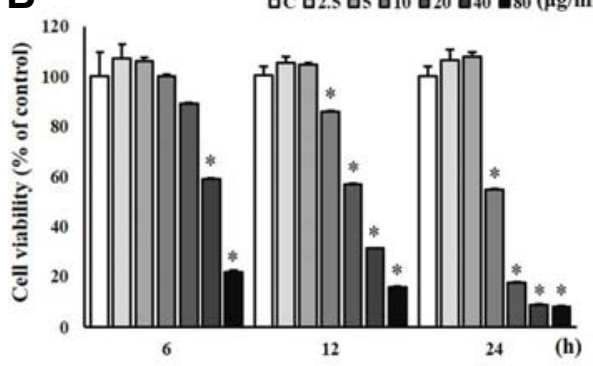

Fig. 1. M. tuberculosis infection and A549 cell viability assay with UA. (A) M. tuberculosis H37Rv was used to infect A549 cells for 2, 3, and $4 \mathrm{~h}$ (multiplicity of infection 10). Following infection, the cells were washed three times with PBS. The cell extracts and supernatants were collected at indicated times and inoculated in $7 \mathrm{H} 9$ medium. Following 15-day incubation, a resazurin assay was performed. The picture of the resazurin plate and the fluorescence intensity were shown. (B) Time- (6-24 h) and concentration $(2.5-80 \mu \mathrm{g} / \mathrm{ml})$-dependent cell viability with UA. Bars represent the mean (expressed as percent of control) \pm S.D. of three independent experiments. * denotes a significant difference relative to control $(p<0.05)$. C stands for control (normal A549 cells).

Both the cytosolic and nuclear extracts were stored at $-80^{\circ} \mathrm{C}$ until use.

\section{Western blot}

Cells were harvested following the desired infection and/or treatment, and proteins were collected by using RIPA lysis buffer containing protease inhibitor cocktail (Santa Cruz Biotechnology, USA). The protein concentration was quantified using a BCA protein assay kit (Pierce, USA). Proteins were separated using a $4-20 \%$ sodium dodecyl sulfate polyacrylamide electrophoresis gradient gel (Mini-PROTEAN ${ }^{\circledR}$ TGX $^{\text {TM }}$ Precast Gel; Bio-Rad, USA) at 100 V for $1.30 \mathrm{~h}$. The separated proteins were transferred to a Trans-Blot SD Semi-Dry Cell polyvinylidene fluoride membrane (Bio-Rad) at $15 \mathrm{~V}$ for 1 $\mathrm{h}$. The membranes were blocked by incubation with $5 \%$ dried skim milk in Tris-buffered saline containing $0.1 \%(\mathrm{v} / \mathrm{v})$ Tween20 (TBST) for $1 \mathrm{~h}$ at room temperature. Membranes were incubated overnight at $4^{\circ} \mathrm{C}$ with primary antibody against iNOS, nuclear factor-kappa B (NF-kB), P65, Lamin B, $\alpha-$ tubulin (all from Santa Cruz Biotechnology), or $\beta$-actin (Abcam, USA). A second incubation was carried out with horseradish peroxidase-conjugated secondary anti-rabbit IgG and antimouse IgG (Santa Cruz Biotechnology) for $1.5 \mathrm{~h}$ at room temperature. The bound antibodies were visualized using enhanced chemiluminescence western blotting detection reagents (Bio-Rad) and images were acquired using a ChemiDoc $^{\top M}$ XRS+ System with Image Lab ${ }^{T M}$ software (BioRad).

\section{qRT-PCR}

Cells were harvested following infection and/or treatment. Total mRNA was collected, quantified, and checked for purity, cDNA was prepared, and qRT-PCR was performed as described previously (Kim et al., 2013). The primers used for human tumor necrosis factor- $\alpha$ (TNF- $\alpha$ ) and glyceraldehyde 3-phosphate dehydrogenase (GAPDH) were 5'-TCTTCTCGAACCCCGAGTGA-3', 5'-CCTCTGATGGCACCACCAG-3' and 5'-TCCCATCACCATCTTCCA-3', 5'-CATCACGCCACAGTTCC-3', respectively. The primer for human interleukin-6 (IL-6) was purchased from Bioneer, catalog no. $\mathrm{N}-1063$ (Korea). The assay results were normalized to the endogenous control gene GAPDH.
Statistical analysis

At least three individual experiments were conducted. Differences between groups were analyzed using one-way analysis of variance followed by the Student's $t$ test, with a $p$-value < 0.05 considered as statistically significant. Data are expressed as the mean \pm standard deviation (SD).

\section{RESULTS}

\section{M. tuberculosis infection and cell viability assay of UA in} A549 cells

To detect successful infection of $M$. tuberculosis inside cells, cell monolayers were infected with $M$. tuberculosis $\mathrm{H} 37 \mathrm{Rv}$ for 2 , 3 , and $4 \mathrm{~h}$ and then washed three times. Supernatants were collected. Cells were lysed using Triton-X 100 and inoculated in $7 \mathrm{H} 9$ media for 15 days. A resazurin assay was performed with un-inoculated medium as a control. The supernatants and uninoculated medium were free of bacteria and remained blue, but the extracts obtained after infected A549 cells disruption were pink (Fig. 1A), indicating that bacteria successfully entered into the cells following infection. Fluorescence intensity data are presented in Fig. 1A. The effect of UA on A549 cells viability was assessed by MTT analysis (Fig. 1B). Both concentration-dependent $(2.5-80 \mu \mathrm{g} / \mathrm{ml})$, and time-dependent $(6-24 \mathrm{~h})$ effects of UA were observed. UA at a concentration of $10 \mu \mathrm{g} / \mathrm{ml}$ did not show any cytotoxic effect at $6 \mathrm{~h}$; these conditions were used in the remaining experiments.

Effect of UA on NO release and cell viability in infected A549 cells and intracellular mycobactericidal activity of A549 cells

NO production was induced in A549 cells upon exposure to $M$. tuberculosis H37Rv (Fig. 2A). Induction was not evident earlier than $48 \mathrm{~h}$ (data not shown) and reached a significant level at 72 $\mathrm{h}$. The induction of NO levels is the indicator of active participation of the alveolar epithelial cells in the innate immune response during $M$. tuberculosis infection. L-NMMA was used to confirm the effect of NO generation during infection. L-NMMA treatment $(5 \mathrm{mM})$ partially reversed $M$. tuberculosis-induced NO release in A549 cells. As the kinetics showed significant induction of NO production at 48 and $72 \mathrm{~h}$, we chose those time 
A
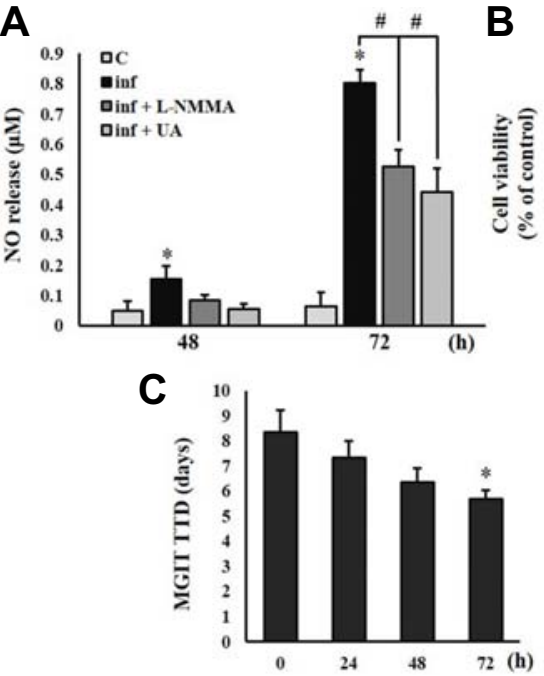

B

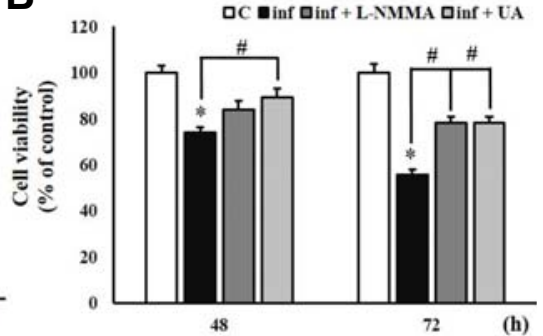

D

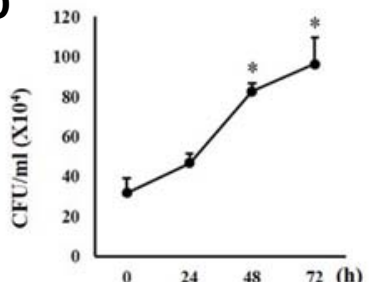

Fig. 2. Effect of UA and L-NMMA on NO release and cytotoxicity in M. tuberculosis infected A549 cells. Additionally intracellular mycobactericidal activity of A549 cells with time. Cells were infected with $M$. tuberculosis H37Rv following treatment with $5 \mathrm{mM} \mathrm{L-NMMA}$ and $10 \mu \mathrm{g} / \mathrm{ml} \mathrm{UA}$ as indicated, and then incubated for 48 and $72 \mathrm{~h}$. NO generation $(A)$ and cell viability $(B)$ were measured. A549 cells were infected with $M$. tuberculosis H37Rv for 0-72 h, cell extracts were prepared, and inoculated in MGIT (C) and $7 \mathrm{H} 11$ agar media (D) for growth. MGIT data is presented as TTD, and colonies in $7 \mathrm{H} 11$ agar media are presented as $\mathrm{CFU} / \mathrm{ml}$. The data are presented as mean \pm S.D. of three independent experiments. *denotes significant differences relative to control $(p<0.05)$ and \# denotes significant difference between 'inf' and 'inf + L-NMMA' or 'inf + UA' $(p<0.05)$. C, inf, L-NMMA, and UA stand for control (normal A549 cells), infection, $N^{G}$-monomethyl-L-arginine, and ursolic acid, respectively.

points for all further observations. The induction of NO generation during infection was significantly reduced by treatment with $\mathrm{UA}$ at $72 \mathrm{~h}$ (Fig. 2A).

Next, we investigated cell viability following $M$. tuberculosis H37Rv infection with or without L-NMMA or UA. Viability was significantly hampered and decreased to a significant degree at both 48 and $72 \mathrm{~h}$. The decrease in cell viability by $M$. tuberculosis infection was partly contributed by NO, as L-NMMA was capable of reversing cell viability to some extent. UA treatment significantly increased cell viability in $M$. tuberculosis H37Rvinfected A549 cells (Fig. 2B).

To correlate NO generation with intracellular mycobactericidal activity in infected A549 cells, MGIT TTD (Fig. 2C), and CFU counts (Fig. 2D) were performed for 0-72 h. The number of bacteria increased, as evident by decreased TTD (days) but increased CFU $/ \mathrm{ml}$ with time. Therefore, the level of $\mathrm{NO}$ generated following $M$. tuberculosis H37Rv infection was insufficient to kill the intracellular mycobacteria. UA treatment under similar treatment conditions did not show mycobactericidal activity (data not shown).

UA inhibits M. tuberculosis-induced expression of iNOS, TNF- $\alpha$, and IL-6 expression

Up-regulation of iNOS was observed in M. tuberculosis H37Rvinfected A549 cells by Western blot (Fig. 3A). The induction started at $24 \mathrm{~h}$ and continued until $72 \mathrm{~h}$. UA (10 $\mu \mathrm{g} / \mathrm{ml})$ successfully suppressed the upregulation of iNOS at $72 \mathrm{~h}$ (Fig. 3B). Densitometry analyses of each western blot data are shown in Fig. 3A and 3B. Expression of TNF- $\alpha$ and IL- 6 was induced following infection of the cells with $M$. tuberculosis H37Rv, which was significantly suppressed by UA treatment at the indicated time points, as determined by qRT-PCR (Figs. 3C and 3D).

UA suppresses M. tuberculosis-induced activation of NF-KB To investigate the involvement of the NF-KB pathway, cytosolic and nuclear extracts were collected after A549 cells were infected and/or treated with UA. Western blots showed that the nuclear NF-KB levels started to increase at $48 \mathrm{~h}$, which was very significantly evident at $72 \mathrm{~h}$. Conversely, the cytosolic lev- els were reduced at $72 \mathrm{~h}$ in $M$. tuberculosis $\mathrm{H} 37 \mathrm{Rv}$-infected A549 cells (Fig. 4A). UA treatment significantly decreased NF$\mathrm{KB}$ accumulation in the nuclei of infected cells (Fig. 4B). The densitometry analyses are presented beneath the respective Western blot data.

\section{DISCUSSION}

The innate immune system is the first line of defense against pathogens before the adaptive immune system takes part. Once inhaled, mycobacteria enter the lung and infect macrophages (Ellner, 1997; Fenton and Vermeulen, 1996; Fulton et al., 1998; Rich et al., 1997). Thus far, studies have mainly focused on the pathogenesis of mycobacteria in alveolar macrophages. However, it is likely that mycobacteria also invade alveolar epithelial cells during TB infection. Mycobacteria can successfully invade and replicate within type II alveolar epithelial cells (Bermudez and Goodman, 1996; Garcia-Perez et al., 2003). Therefore, epithelial cells are not innocent bystanders; rather, they have significant roles in innate immunity and inflammatory responses (Gribar et al., 2008). Our data demonstrate that mycobacteria successfully infect and replicate in alveolar epithelial A549 cells. Along with anti-carcinogenic, antiinflammatory, antioxidant, and pro-apoptotic properties, UA also has anti-TB potential (Jiménez-Arellanes et al., 2013; Podder et al., 2015). Our goal was to detect the role of UA in mycobacteria-infected alveolar epithelial A549 cells in the context of NO generation and cell viability. NO plays an important role in inflammation, where it is produced by iNOS, which is responsive to interferon-gamma (IFN-y). IFN-y stimulation of A549 cells increases NO production (Guzik et al., 2003; Xie and Nathan, 1994). Therefore, NO that is produced due to mycobacterial infection in A549 cells may be attributed to the de novo synthesis of IFN-y in these cells. Nonetheless, susceptibility to NO differs markedly from cell to cell. Increased NO-mediated cell death may be related to DNA or mitochondrial damage (Murphy, 1999). Presently, increased production of NO was critical for cell viability and mycobactericidal activity. With increasing NO concentrations, cytotoxicity also increased with time, even 
A
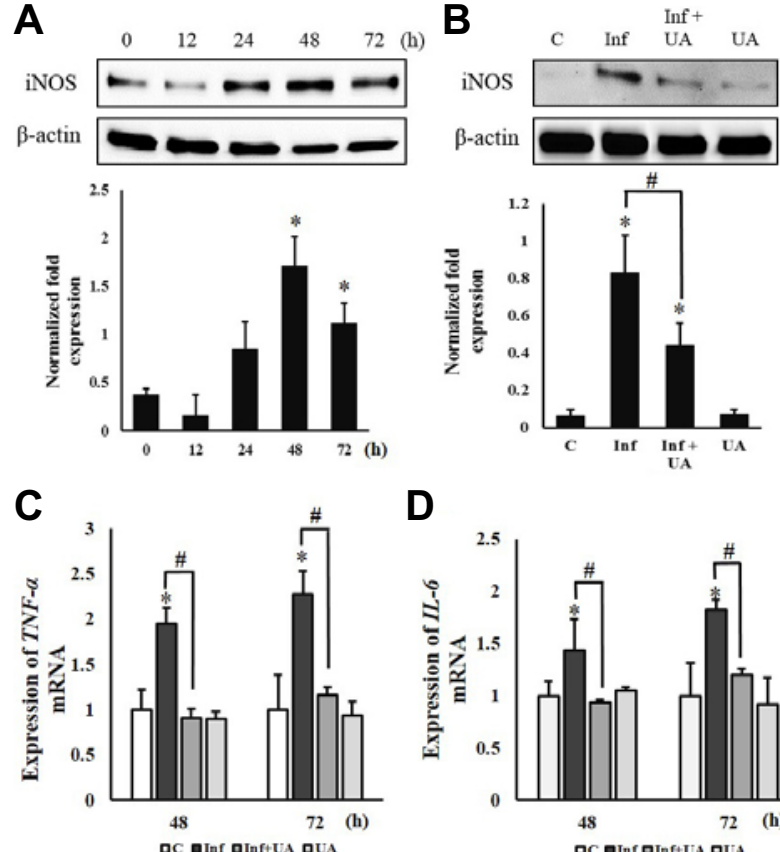

D

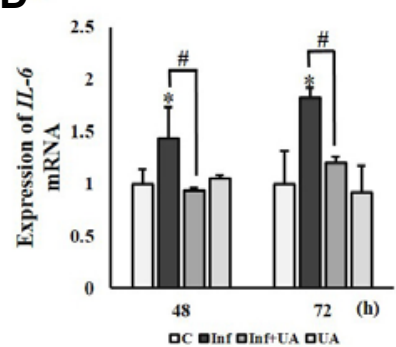

Fig. 3. Effect of UA on M. tuberculosis-induced iNOS, TNF- $\alpha$, and IL-6 expression. A549 cells were infected with $M$. tuberculosis H37Rv for $2 \mathrm{~h}$, washed three times and incubated for 0-72 h. Western blot analysis was performed to detect the iNOS expression levels (A). iNOS expression was detected in $M$. tuberculosis H37Rv-infected and/or $10 \mu \mathrm{g} / \mathrm{ml}$ UA-treated A549 cells after $72 \mathrm{~h}$ by Western blot $(B) . \beta$-actin was the endogenous control. The densitometry analyses are presented beneath the respective Western blot data. A549 cells were infected with M. tuberculosis H37Rv and/or treated with $10 \mu \mathrm{g} / \mathrm{ml}$ UA for 48 and $72 \mathrm{~h}$. Cells were harvested, the total mRNA was collected, cDNA was prepared, and qRT-PCR was performed to detect TNF- $\alpha$ and IL- 6 mRNA expression. The data are presented as mean \pm S.D. of three independent experiments. * denotes significant differences relative to control $(p<0.05)$ and \# denotes significant difference between 'inf' and 'inf + UA' $(p<0.05)$. C, inf, and UA stand for control (normal A549 cells), infection, and ursolic acid, respectively.

though the level of NO was insufficient to kill intracellular mycobacteria. A previous report provided a similar interpretation, where the increased NO generated due to mycobacterial infection was insufficient to kill intracellular mycobacteria in A549 cells (Roy et al., 2004). Hence, surrounding inflammatory cytokines from monocytes/macrophages might be required to generate the increased amount of NO to kill intracellular mycobacteria. This NO level would be highly cytotoxic to normal cells. Another potential reason for A549 epithelial cell death is virulent M. tuberculosis H37Rv infection resulting in apoptosis and necrosis (Danelishvili et al., 2003).

The anti-carcinogenic, anti-inflammatory, and pro-apoptotic activities of UA are due to its ability to inhibit the immunoregulatory transcription factor, NF-kB, in response to a variety of carcinogens and inflammatory agents (Shishodia et al., 2003). After taking into account that UA is a triterpenoid carboxylic acid, it is not surprising that this compound possesses potent antiinflammatory and cytotoxic activities and is a potent inhibitor of NF-kB activation (De las Heras et al., 2003; Yang et al., 2002;
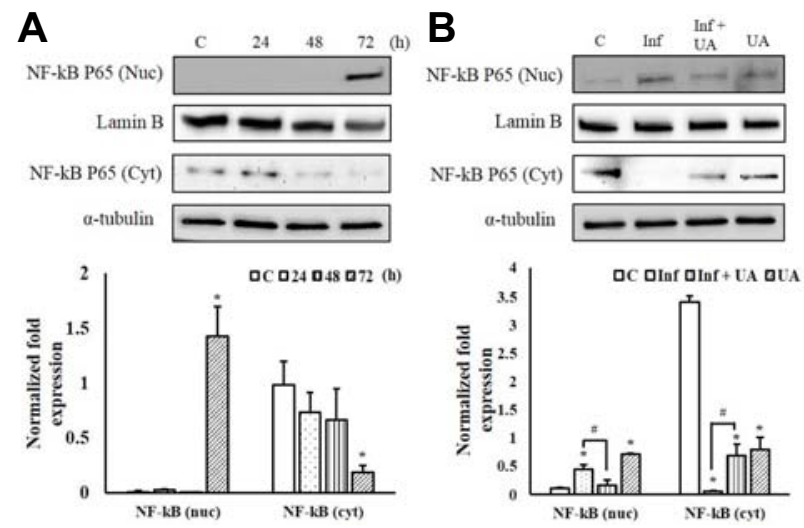

Fig. 4. Effect of UA on M. tuberculosis-induced NF-KB activation. Translocation of NF-KB P65 from the cytosol to nucleus signifies its activation as a transcription factor. Nuclear and cytosolic extracts were collected and quantified, and Western blotting was performed. (A) M. tuberculosis H37Rv-infected A549 cells were incubated for 0$72 \mathrm{~h}$, and their cytosolic and nuclear NF-KB P65 levels were observed by Western blot analysis. (B) Translocation of NF-KB P65 was also evaluated in $M$. tuberculosis $\mathrm{H} 37 \mathrm{Rv}$-infected and/or 10 $\mu \mathrm{g} / \mathrm{ml}$ UA-treated A549 cells at $72 \mathrm{~h}$. Lamin B and $\alpha$-tubulin were the endogenous controls of nuclear and cytosolic proteins, respectively. Densitometry analyses are presented beneath the respective Western blot data. The data are presented as mean \pm S.D. of three independent experiments. * denotes significant differences relative to control $(p<0.05)$ and \# denotes significant difference between 'inf' and 'inf + UA' $(p<0.05)$. C, inf, and UA stand for control (normal $A 549$ cells), infection, and ursolic acid, respectively.

2003). UA partially inhibited the activation of NF-kB and its downstream pro-inflammatory cytokines, TNF- $\alpha$ and IL-6, in mycobacteria-infected alveolar epithelial cells. The observations indicate the anti-inflammatory potential of UA and support the previous description of the activation of NF-KB $48 \mathrm{~h}$ after $M$. tuberculosis H37Rv infection in human THP-1 cells (Dhiman et al., 2007).

Our results strongly suggest that alveolar epithelial cells act as the first line of defense against mycobacteria by inducing $\mathrm{NO}$ generation. The levels of NO generated directly following infection of A549 cells with mycobacteria are insufficient to kill intracellular mycobacteria. However the bacterial count increased with time. Interestingly, the increased production of NO due to mycobacterial infection showed an increasing cytotoxicity in A549 cells. This cytotoxic effect was partially reversed by treating cells with UA following mycobacterial infection, which is attributed to the reduction of NO production in infected A549 cells. The induced activation of the immunoregulatory transcription factor, NF-kB following infection was also significantly quenched by UA. Taken together, our data reveal the critical role of $\mathrm{NO}$ in mycobacterial infection and the protective role of UA in mycobacteria-infected A549 cells.

\section{ACKNOWLEDGMENTS}

This work was supported by a Grant of the Ministry of Health \& Welfare R\&D Project, Republic of Korea (HI13C0828).

\section{REFERENCES}

Bermudez, L.E., and Young, L.S. (1994). Factors affecting invasion 
of HT-29 and HEp-2 epithelial cells by organisms of the Mycobacterium avium complex. Infect Immun. 62, 2021-2026.

Bermudez, L.E., and Goodman, J. (1996). Mycobacterium tuberculosis invades and replicates within type II alveolar cells. Infect Immun. 64, 1400-1406.

Chan, J., Xing, Y., Magliozzo, R., and Bloom, B.R. (1992). Killing of virulent Mycobacterium tuberculosis by reactive nitrogen intermediates produced by activated murine macrophages. J. Exp. Med. 175, 1111-1122.

Danelishvili L., McGarvey J., Li Y.J., and Bermudez L.E. (2003). Mycobacterium tuberculosis infection causes different levels of apoptosis and necrosis in human macrophages and alveolar epithelial cells. Cell Microbiol. 5, 649-660.

De las Heras, B., Rodrí guez, B., Boscá, L., and Villar, A.M. (2003). Terpenoids: sources, structure elucidation and therapeutic potential in inflammation. Curr. Top Med. Chem. 3, 171-185.

Dhiman, R., Raje, M., and Majumdar, S. (2007). Differential expression of NF-kappaB in mycobacteria infected THP-1 affects apoptosis. Biochim. Biophys. Acta 1770, 649-658.

Eizirik, D.L., Flodström, M., Karlsen, A.E., and Welsh, N. (1996) The harmony of the spheres: Inducible nitric oxide synthase and related genes in pancreatic beta cells. Diabetologia 39, 875-890.

Ellner, J.J. (1997). Review: The immune response in tuberculosis: implication for tuberculosis control. J Infect Dis. 176, 1351-1359.

Fenton, M.J., and Vermeulen, M.W. (1996). Immunopathology of tuberculosis: Roles of macrophages and monocytes. Infect Immun. 64, 683-690.

Fulton, S.A., Cross, J.V., Toossi, Z.T., and Boom, W.H. (1998). Regulation of interleukin-12 by interleukin 10, transforming growth factor-b, tumour necrosis factor-a and interferon-c in human monocytes infected with Mycobacterium tuberculosis H37Ra. J. Infect Dis. 178, 1105-1114.

Garcia-Perez, B.E., Mondragon-Flores, R., and Luna-Herrera, J. (2003). internalization of Mycobacterium tuberculosis by macropinocytosis in non-phagocytic cells. Microb. Pathog. 35, 49-55.

Gribar, S.C., Anand, R.J., Sodhi, C.P., and Hackam, D.J. (2008). The role of epithelial Toll-like receptor signaling in the pathogenesis of intestinal inflammation. J. Leukoc. Biol. 83, 493-498.

Guzik, T.J., Korbut, R., and Adamek-Guzik, T. (2003). Nitric oxide and superoxide in inflammation and immune regulation. J. Physiol Pharmacol. 54, 469-487.

Ignarro, L.J. (2000). Introduction and overview, in Nitric Oxide, Biology and Pathobiology, ed. Ignarro, L.J. (Academic, San Diego), pp 3-19.

Ikeda, Y., Murakami, A., and Ohigashi, H. (2008). Ursolic acid: an anti- and proinflammatory triterpenoid. Mol. Nutr. Food Res. 52 , 26-42.

Jiménez-Arellanes, A., Luna-Herrera, J., Cornejo-Garrido, J., López-García, S., Castro-Mussot, M.E., Meckes-Fischer, M. Mata-Espinosa, D., Marquina, B., Torres, J., and HernándezPando, R. (2013). Ursolic and oleanolic acids as antimicrobia and immunomodulatory compounds for tuberculosis treatment. BMC Complement. Altern. Med. 13, 258.
Kim, Y.S., Zerin, T., and Song, H.Y. (2013). Antioxidant action of ellagic acid ameliorates paraquat-induced A549 cytotoxicity. Biol. Pharm. Bull. 36, 609-615.

Liu, J. (1995). Pharmacology of oleanolic acid and ursolic acid. J. Ethnopharmacol. 49, 57-68.

Mapother, M.E., and Sanger, J.G. (1984). In vitro interaction of Mycobacterium avium with intestinal epithelial cells. Infect Immun. 45, 67-73.

Murphy, M.P. (1999). Nitric oxide and cell death. Biochim. Biophys. Acta $1411,401-414$

Podder, B., Jang, W.S., Nam, K.W., Lee, B.E., and Song, H.Y. (2015). Ursolic acid activates intracellular killing effect of macrophage in Mycobacterium tuberculosis infection. J. Microbiol. Biotechnol. 25, 738-744.

Rich, E.A., Torres, M., Sada, E., Finegan, C.K., Hamilton, B.D., and Toossi, Z. (1997). Mycobacterium tuberculosis stimulated production of nitric oxide by human alveolar macrophages and relationship of nitric oxide production to growth inhibition of MTB. Tubercle Lung Dis. 78, 247-255.

Roy, S., Sharma, S., Sharma, M., Aggarwal, R., and Bose, M. (2004). Induction of nitric oxide release from the human alveolar epithelial cell line A549: an in vitro correlate of innate immune response to Mycobacterium tuberculosis. Immunology 112, 471 480.

Shepard, C.C. (1955). Phagocytosis by HeLa cells and their susceptibility to infection by human tubercle bacilli. Proc. Soc. Exp. Biol. Med. 90, 392-396.

Shishodia, S., Majumdar, S., Banerjee, S., and Aggarwal, B.B. (2003). Ursolic acid inhibits nuclear factor-kappaB activation induced by carcinogenic agents through suppression of IkappaB alpha kinase and p65 phosphorylation: correlation with downregulation of cyclooxygenase 2 , matrix metalloproteinase 9 , and cyclin D1. Cancer Res. 63, 4375-4383.

Smith, D.W., Wiegeshaus, E., Navakar, R., and Grover, A.A. (1966). Host-parasite relationships in experimental airborne tuberculosis. J. Bacteriol. 91, 718-724.

Stuer, D.J., Gross, S.S., Sukuma, I., Levi, R., and Nathan, C.F. (1989). Activated murine macrophages secrete a metabolite of arginine with the bioactivity of endothelium-derived relaxing factor and the chemical reactivity of nitric oxide. J. Exp. Med. 169, 1011-1020.

Tsai, S.J., and Yin, M.C. (2008). Antioxidative and anti-inflammatory protection of oleanolic acid and ursolic acid in PC12 cells. J. Food Sci. 73, H174-H178.

Xie, Q., and Nathan, C. (1994). The high-output nitric oxide pathway: role and regulation. J. Leukoc. Biol. 56, 576-582.

Yang, J., Hooper, W.C., Phillips, D.J., and Talkington, D.F. (2002). Regulation of proinflammatory cytokines in human lung epithelial cells infected with Mycoplasma pneumoniae. Infect Immun. 70, 3649-3655.

Yang, J., Hooper, W.C., Phillips, D.J., Tondella, M.L., and Talkington, D.F. (2003). Induction of proinflammatory cytokines in human lung epithelial cells during Chlamydia pneumoniae infection. Infect Immun. 71, 614-620. 